\title{
Use of anti-D in an accident and emergency department
}

\author{
A. M. HUGGON \& D. P. WATSON \\ Accident and Emergency Department, Guy's Hospital, St Thomas Street, London SE1 \\ 9RT
}

\section{SUMMARY}

A retrospective study was made of the use of anti-D in an accident and emergency (A\&E) department in 1 month.

Patients who are discharged home with a diagnosis of threatened miscarriage should have their blood group determined and anti-D should be given to those who are rhesus negative.

We found that only $8 / 29$ patients discharged from the department had their blood group determined and none of the rhesus negative patients was given? anti-D.

We have introduced a practical method of reminding medical staff to give anti-D to patients who require it.

\section{INTRODUCTION}

There are clear guidelines for the use of anti-D immunoglobulin both during pregnancy and post-delivery (Lee et al., 1991). Perinatal losses due to Rh haemolytic disease have been reduced dramatically since anti-D was introduced (Hussey \& Clarke 1991; Selinger, 1991). However, a small number of pregnant rhesus negative women (approximately 1\%) become immunized each year in spite of the availability of prophylaxis. 


\section{PATIENTS AND METHODS}

A retrospective review was made of patients presenting to the A\&E department in February 1992 with vaginal bleeding in pregnancy who were discharged home. Those patients who were admitted to hospital or were seen solely by a gynaecologist were excluded from the study.

In each case the gestation of pregnancy, clinical diagnosis and maternal blood group details were noted.

\section{RESULTS}

A total of 39 patients were seen by the A\&E medical staff. Of these, 29 were discharged home, either directly from the department or following review by the gynaecology senior house officer. The blood group was checked in only eight of these 29 patients.

It was possible to determine the blood group of a further 12 patients through the blood transfusion laboratory (from samples taken on previous or subsequent occasions).

A total of five patients were found to be rhesus negative. One of these was known to be rhesus negative at the time of discharge; one had had a sample taken but the result was not retrieved. The remaining three were discharged without the blood group being determined. None of these five patients received anti-D when they were discharged (Table 1). One patient was admitted subsequently with increased bleeding and was given anti-D at that time.

\section{DISCUSSION}

Prevention of rhesus haemolytic disease is safe and simple; treatment includes invasive procedures such as intrauterine transfusion. Awareness of the need for anti-D administration following potential sensitizing events is the key to prevention (Table 2).

Women who have bleeding in pregnancy commonly present to the $A \& E$

Table 1. Management of rhesus negative patients with threatened miscarriage

\begin{tabular}{lcc}
\hline $\begin{array}{l}\text { Gestation } \\
\text { (weeks) }\end{array}$ & Blood group done & Anti-D given \\
\hline 6 & yes & no \\
$9^{+5}$ & yes & no \\
12 & no & no \\
$15^{+4}$ & no & no \\
16 & no & no \\
\hline
\end{tabular}


Table 2. Potential sensitizing events for a rhesus negative woman

\begin{tabular}{l} 
Abortion \\
threatened \\
spontaneous \\
induced \\
Ectopic pregnancy \\
Abdominal trauma \\
Obstetric \\
invasive investigations \\
antepartum haemorrhage \\
external cephalic version \\
delivery \\
Rhesus positive blood transfusion \\
\hline
\end{tabular}

Table 3. Indications for anti-D in rhesus negative women with miscarriage

Threatened - any gestation

Complete $>12$ weeks

Evacuation of retained products of conception

department. Determining maternal rhesus status should form part of their assessment, and anti-D given as appropriate. The blood group will be recorded on the patient's ante natal card if she has been booked into ante natal clinic; otherwise a sample should be taken.

The recommendations for the use of anti-D in miscarriage are given in Table 3. It can be seen that anti-D should be given to rhesus negative women with threatened miscarriage of any gestation, or a complete miscarriage of greater than 12 weeks gestation. Rhesus negative women who undergo an evacuation of retained products of conception (ERPC) for incomplete or missed abortion will be given anti-D on the ward.

For pregnancies of less than 20 weeks gestation 250 i.u. of anti-D are given intramuscularly within $96 \mathrm{~h}$ of the onset of bleeding. This should be repeated at 6-weekly intervals if bleeding continues intermittently. Anti-D is not required if the patient already has immune anti-D. The recommendations for other events, e.g. antepartum haemorrhage, are not given as these patients would be admitted.

It is recommended that the patient's blood group is determined before discharge so that anti-D can be given when appropriate. However, if this is difficult (e.g. during the night) and the patient is returning well within the 96-h limit for an ultrasound scan, then the result can be retrieved on the second attendance.

In this small study, $21 / 29(72 \%)$ patients had no rhesus status recorded; this was marginally better than a similar Canadian study in which $38 / 44(86 \%)$ blood groups were unrecorded (Grant \& Hyslop 1991). It is a cause for concern that none of the patients were given anti-D.

In order to remedy this situation, we have introduced a practical reminder for the medical staff. A stamp is kept with the pregnancy testing kits and this is used 


\begin{tabular}{|l|l|l|}
\hline Pregnancy test & Rh status & ? anti - D required \\
\hline & & \\
\hline
\end{tabular}

Fig. 1. Stamp placed on records when pregnancy test performed.

by the nursing staff to record the result. This acts as an automatic prompt to consider the need for anti-D in pregnant patients (Fig. 1).

In drawing up the recommendations for the use of anti-D immunoglobulin in miscarriage, the National Blood Transfusion Service Immunoglobulin Working Party recognized that they were 'necessarily somewhat empirical given the paucity of data on transplacental haemorrhage and subsequent immunization in association with the loss of pregnancy'. However, in view of the availability of safe and effective prophylaxis and clear guidelines for its use, prevention of rhesus haemolytic disease is an important part of the management of women with miscarriage.

\section{REFERENCES}

Grant J. \& Hyslop M. (1991) Underutilisation of $\mathrm{Rh}$ prophylaxis in the emergency department: a retrospective survey. Annals of Emergency Medicine 21(2), 181-183.

Hussey R. M. \& Clarke C. A. (1991) Deaths from Rh haemolytic disease in England and Wales in 1988 and 1989. British Medical Journal 303, 445-446.

National Blood Transfusion Service Immunoglobulin Working Party (1991) Recommendations for the use of anti-D immunoglobulin. Prescribers' Journal 31(4), 137-145.

Selinger M. (1991) Immunoprophylaxis for rhesus disease - expensive but worth it? British Journal of Obstetrics and Gyitaecology 98, 509-512. 